\title{
SHEAR BOND STRENGTH OF COMPOSITE REPAIR MATERIAL TO CERAMO-METALLIC AND ZIRCONIUM RESTORATIONS USING A NEW ADHESIVE SYSTEM
}

\author{
Mohamed Masoud Ahmed Marouf ${ }^{1}$, Mosaad Aly El-Gabrouny², Amr Abd El-Aziz Shebl ${ }^{3}$, \\ Rania El-Saady Badawy ${ }^{4}$
}

DOI: $10.21608 / d s u .2020 .16645 .1010$

\section{KEYWORDS}

Single bond universal adhesive,

Veneering porcelain,

Zirconia

- E-mail address:

drmmm86@hotmail.com

1. B.D.S (2008), October 6 University, Dentist in Egyptian Ministry of Health

2. Professor in Crown and Bridge Department-Faculty of Dentistry, Suez Canal University

3. Lecturer in Crown and Bridge Department, Faculty of Dentistry, Suez Canal University

4. Assistant professor in Dental Material Department, Faculty of Dentistry, Suez-Canal University

\section{ABSTRACT}

Introduction: Clinical success of ceramic repair system is dependent on integrity of bond between metal, ceramic and resin composite. Aim: Evaluate shear bond strength (SBS) of composite repair material to ceramo-metalic and zirconium restorations using new adhesive system after thermocycling. Materials and methods: 28 square specimens of metal, zirconia, veneering porcelain for metal (VMK95) and veneering porcelain for zirconia (VM9) were prepared $(1 \times 1 \times 0.5 \mathrm{~cm})$ and divided into 4 groups: 1)metal (M) group , 2)zirconia (Z) group , 3)veneering porcelain for metal (VPM) group, 4)veneering porcelain for zirconia(VPZ) group). Then $\mathrm{M}$ and $\mathrm{Z}$ groups were sandblasted while VPM and VPZ groups were subjected to HF acid. Single bond universal adhesive were applied to exposed surface of all groups then repair composite material was built up incrementally over center of exposed surface using cylindrical teflon mold ( 3 x $5 \mathrm{~mm}$ ), stored for 7 days in distilled water followed by 1000 thermocycles then SBS was tested. Results: Highest SBS value between composite repair material and $\mathrm{M}$ group followed by $\mathrm{Z}$ group and composite repair material then VPM group and composite repair material then VPZ group and composite repair material. Conclusions: Sandblasting and application of single bond universal adhesive containing MDP can be recommended for repair metal and zirconium surfaces with composite material. HF acid etching and application of single bond universal adhesive containing MDP can be recommended for repair VPM and VPZ with composite repair material.

\section{INTRODUCTION}

Repair may be indicated when a fractured restoration continues to fulfill the requirements for preserving dental-periodontal health, without any need for replacement ${ }^{(1)}$. Furthermore, factors such as elevated cost, possible trauma to restored tooth, lack of time, and difficulty of removing the restoration may occasionally delay the replacement of fractured restorations ${ }^{(2)}$.

The clinical success of ceramic repair system is almost dependent on the integrity of bond between the ceramic and the resin composite. This integrity is achieved either by chemical or mechanical bond ${ }^{(3)}$.

Dental adhesive systems were initially introduced for bonding composites to mineralized tooth structures ${ }^{(4)}$. Recently, the newer 
generations of adhesive systems are multipurpose systems capable of bonding to various substrates. These new systems are used for bonding composite materials to enamel, dentin, metal, porcelain and even zirconia ${ }^{(5)}$.
With this development in tooth-colored restorations and newer generations of multipurpose adhesive systems, it is essential to investigate the bond strength of these materials to various substrates, especially metal, porcelain and zirconia.

\section{MATERIALS AND METHODS}

\section{Materials}

Materials used in this study listed in the following table:

\begin{tabular}{|c|c|c|c|}
\hline Material & Brand name & Main composition & Manufacturer/country \\
\hline Nickel Chromium alloy & $\begin{array}{l}\text { NIDUR Ni-Cr dental } \\
\text { alloy }\end{array}$ & $\begin{array}{c}\text { Ni } 62 \%, \text { Cr } 24.50 \%, \text { Mn } 10.30 \%, \mathrm{Si} \\
1.70 \%, \text { Fe } 1.50 \% \text {,Traces Co, C }\end{array}$ & DFS DIAMON, Germany \\
\hline $\begin{array}{l}\text { Veneering porcelain for } \\
\text { metal }\end{array}$ & $\begin{array}{l}\text { VMK95 METAL } \\
\text { KERAMIC }\end{array}$ & $\begin{array}{l}\text { feldspathic mixture of anhydrated alumi- } \\
\text { no-silicates powder } \mathrm{K}_{2} \mathrm{O}, \mathrm{Al}_{2} \mathrm{O}_{3}, 6 \mathrm{Si} \mathrm{O} \mathrm{O}_{2}\end{array}$ & $\begin{array}{l}\text { VITA Zahnfabrik, Bad } \\
\text { Sackingen, Germany }\end{array}$ \\
\hline $\begin{array}{l}\text { Veneering porcelain for } \\
\text { zirconium }\end{array}$ & Base Dentine Vita VM.9 & $\begin{array}{l}\text { biological porcelain ceramic zirconium } \\
\text { oxide powder }\end{array}$ & $\begin{array}{l}\text { VITA Zahnfabrik, Bad } \\
\text { Sackingen, Germany }\end{array}$ \\
\hline Zirconium blocks & $\begin{array}{l}\text { AmannGirrbachZir con- } \\
\text { oxidrohlingeceramillzi } 31\end{array}$ & Yttria partially stabilized zirconia & Berlin, Deutschland \\
\hline Composite resin material & Filtek Z350XT composite & $\begin{array}{l}\text { BisGMA, TEGDMA, zirconium, silica } \\
\text { fillers, camphor quinone }\end{array}$ & $\begin{array}{l}\text { 3M ESPE AG Dental prod- } \\
\text { ucts, Seefeld, Germany }\end{array}$ \\
\hline Bonding resin & Single Bond Universal & $\begin{array}{c}\text { Organophosphate monomer(MDP) } \\
\text { dimethacrylate resins(BisGMA,etc) } \\
\text { HEMA,Vitrebond copolymer,filler,ethane } \\
\text {,water,initiators,silane }\end{array}$ & $\begin{array}{l}\text { 3M Deutschland } \mathrm{GmbH} \\
\text { Dental products, Neuss, } \\
\text { Germany }\end{array}$ \\
\hline Hydrofluoric acid gel & $\begin{array}{l}\text { Dento Bond porcelain } \\
\text { Etch }\end{array}$ & $\begin{array}{l}\text { Specially buffered viscous hydrofluoric } \\
\text { acid }(8 \%)\end{array}$ & $\begin{array}{l}\text { ITENA Dental products, } \\
\text { Paris, France }\end{array}$ \\
\hline
\end{tabular}

\section{METHODOLOGY}

A total of 28 square specimens ${ }^{(6,7)}$ were divided into 4 groups, 7 specimens for each group of metal, zirconia, veneering porcelain for metal and veneering porcelain for zirconia $(1 \mathrm{~cm} \times 1 \mathrm{~cm}$ dimensions and 0.5 $\mathrm{cm}$ thickness) were prepared as the following:

\section{Specimens preparation}

a. Metal specimens (M): Seven metal squares were prepared as the following: blue inlay casting wax (Crown wax, Bego, Germany) was melted with dental wax heater (Dentist dental 3 well analog wax melting dipping pot heater melter lab equipment, China) and poured into a square Teflon split mold $(1 \mathrm{~cm} \times 1 \mathrm{~cm}$ dimensions and $0.5 \mathrm{~cm}$ thickness) (Figure 1). After complete cooling of the wax squares, wax sprue former were attached using sticky wax, then wax squares were invested in casting ring and embedded in a phosphate-bonded investment (Bella vest SH, Bego, Germany) (Figure 2). After complete setting of the investment; the ring was placed in a burn out oven (Dental burn- 
out wax oven, Zhengzhou Kejia Furance Co, China) to eliminate the wax, the temperature was gradually increased from room temperature to $300^{\circ} \mathrm{C}$ in 30 minutes and raised up to $850^{\circ} \mathrm{C}$ for 1 hour. The molds were casted with melted $\mathrm{Ni}-\mathrm{Cr}$ alloy using an induction casting machine (Ducatron Quattro centrifugal induction casting machine from Ugin Dentaire, France) according to manufacturer recommendations. Cast rings were allowed to cool at room temperature, then specimens were divested and all sprues were cut using metal cutting discs. All specimens were ultrasonically cleaned in distilled water for 15 minutes to remove any investment material and air dried to be checked microscopically for any porosity. In order to hold the specimens in place for testing, they were embedded in autopolymerizing acrylic resin in a rubber base mold $(1.5 \mathrm{~cm} \times 2 \mathrm{~cm})$ so that only one side of the mold (the testing surface) was exposed. To prevent the testing surfaces from being covered with acrylic resin, the testing surfaces of the specimens were covered with gluey tape before pouring resin and the tape was removed after complete polymerization of the acrylic resin (Figure $3)$. Finally the embedded metal specimens in acrylic block were shown as in (Figure 4).

b. Zirconia specimens $(\mathbf{Z})$ : Seven square specimens were cut from zirconia blocks using a low speed saw (MICRACUT 125 Low speed precision cutting saw, Metlab Corp. USA) with $25 \%$ larger dimensions to compensate sintering shrinkage (each of $1.25 \mathrm{~cm} \times 1.25 \mathrm{~cm}$ dimensions and $0.75 \mathrm{~cm}$ thickness). Cut specimens were sintered in a sintering furnace (Kijia dental zirconia sintering furance, Zhengzhou Kejia Furnace Co., Ltd. China) according to the manufacturer's instructions to obtain square specimens (each of $1 \mathrm{~cm} \times 1 \mathrm{~cm}$ dimensions and $0.5 \mathrm{~cm}$ thickness) and embedded in acrylic block of $1.5 \mathrm{~cm} \times 2 \mathrm{~cm}$ dimension similar to metal specimens (Figure 5).

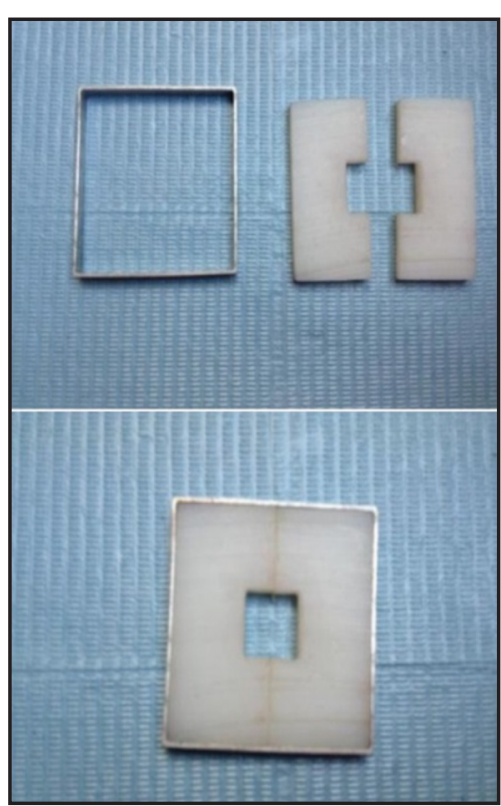

Fig. (1) Teflon split mold

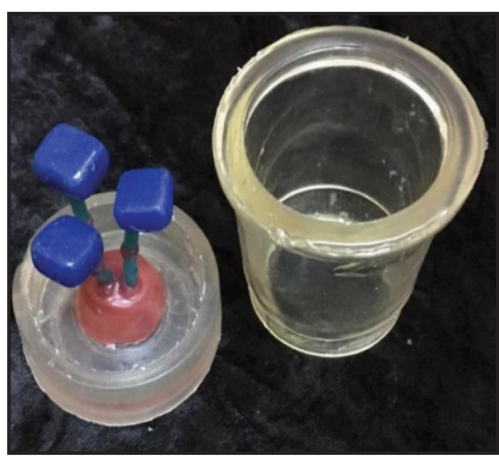

Fig. (2) Wax squares and casting ring

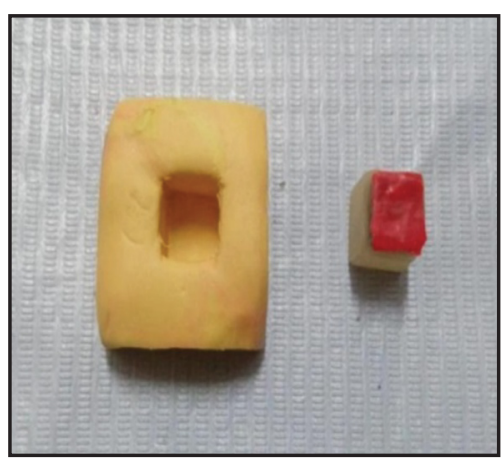

Fig. (3) Rubber base mold for acrylic blocks and specimen covered with gluey type 


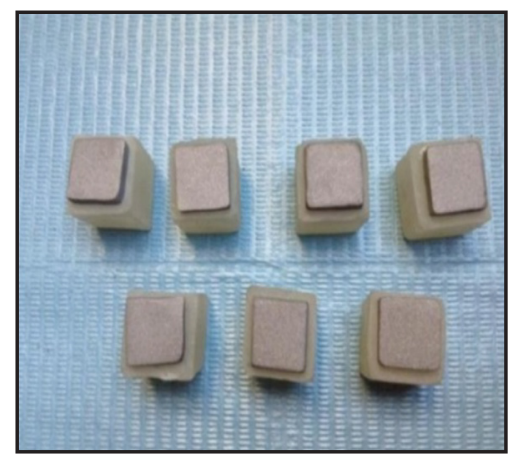

Fig. (4) Metal specimens embedded in acrylic blocks

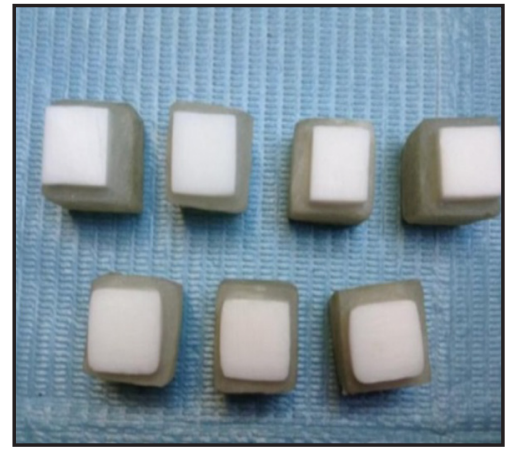

Fig. (5) Zirconia specimens embedded in acrylic blocks

c. Veneering porcelain for metal specimens $(\boldsymbol{V P M})$ : Dentin porcelain powder (VMK95 metal ceramic) was mixed with distilled water into a paste to fill a Teflon split mold of $1 \mathrm{cmx} 1 \mathrm{~cm}$ dimensions and $0.5 \mathrm{~cm}$ thickness on an aluminum foil strip. Afterwards, the specimens were fused in a porcelain oven (Programat p300/g2 porcelain oven, Ivoclarvivadent Inc. USA ) according to manufacturer's instructions, while more porcelain paste was added to compensate for the fusion shrinkage. The process is repeated until the desired dimensions of the seven specimens were reached $(1 \mathrm{~cm} \times 1 \mathrm{~cm} \times 0.5 \mathrm{~cm})$. These specimens were further embedded in similar acrylic resin blocks of $1.5 \mathrm{~cm} \times 2 \mathrm{~cm}$ dimensions (Figure 6 ).

d. Veneering porcelain for zirconia (VPZ): Dentin porcelain powder (Base dentine vita VM.9) was mixed with distilled water into a paste to fill a Teflon split mold of $1 \mathrm{~cm} \times 1 \mathrm{~cm}$ dimensions and $0.5 \mathrm{~cm}$ thickness on aluminum foil strip. Afterwards, the specimens were fused in a porcelain oven according to manufacturer's instructions, while more porcelain paste was added to compensate for the fusion shrinkage. The process is repeated until the desired dimensions of the seven specimens were reached $(1 \mathrm{~cm} \times 1 \mathrm{~cm} \times 0.5 \mathrm{~cm})$, which were further embedded in similar acrylic blocks of $1.5 \mathrm{~cm} \times 2 \mathrm{~cm}$ dimensions (Figure 7).

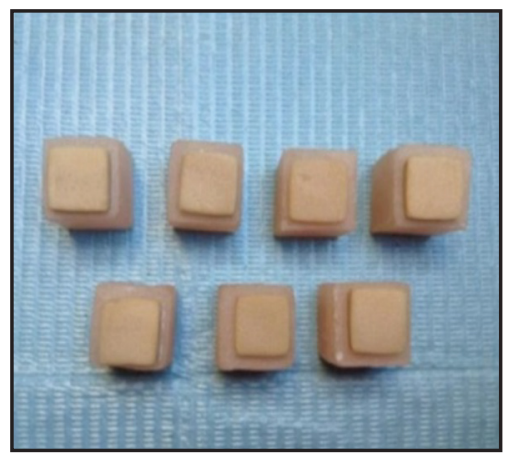

Fig. (6) Porcelain specimens for metal veneering embedded in acrylic blocks

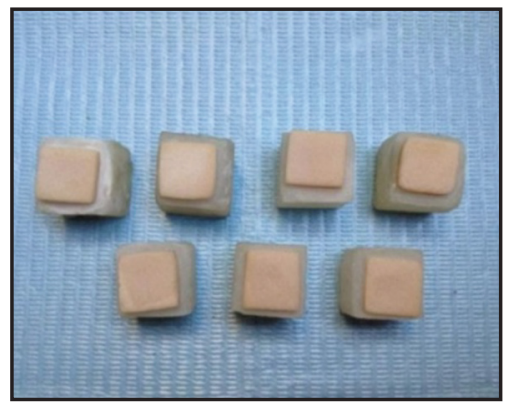

Fig. (7) Porcelain specimens for zircontia veneering embedded in acrylic blocks

\section{Specimens surface treatment}

a. Metal and zirconia specimens were sandblasted using an intraoral prophy jet unit (Air prophy unit, Guangzhou, Guangdong. China) (Figure 8) with $50 \mu \mathrm{m}$ aluminum oxide particles at an air pressure of 2 bar from $10 \mathrm{~mm}$ distance for 
$20 \mathrm{sec}$ perpendicular (angle $90^{\circ}$ ) to the surface. Then the specimens were air-splitted softly to remove excessive sandblasting powder.

b. Veneering porcelain for metal and veneering porcelain for zirconia specimens were etched with hydrofluoric acid gel $8 \%$ using a small brush for 60 seconds. The etched surface was thoroughly rinsed with water to be dried afterwards to completely remove the etchant, finally giving a frosty white appearance.

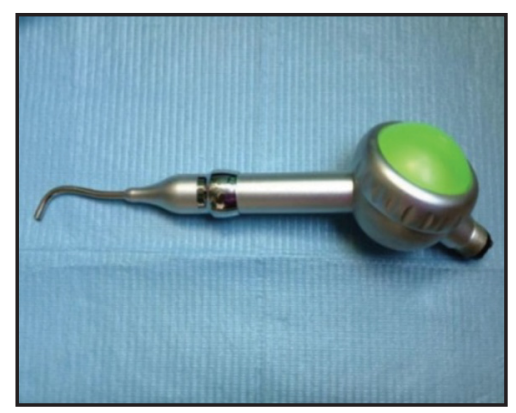

Fig. (8) Intraoral Profijet unit

\section{Adhesive and composite repair material}

Single bond universal adhesive was applied according to the manufacturer's instructions using a small brush to exposed surface of all the specimens, and was rubbed in for $20 \mathrm{sec}$. Afterwards, a gentle stream of air was directed over the liquid for about $5 \mathrm{sec}$ until the solvent completely evaporated. The bond was then hardened with a LED curing light device (LiteQ LD-107, Monitex,Tayiwan) for 10 sec. To insure complete bonding of composite repair material to the exposed surface of the specimens, composite material approximately was built up incrementally ( $1.5 \mathrm{~mm}$ for each layer) over the center of the exposed surface of the specimens using a custom made cylindrical Teflon mold ( $3 \mathrm{~mm}$ height and 5mm diameter) (Figure 9). Composite repair material was cured for $20 \mathrm{sec}$ at adistance of $1 \mathrm{~mm}$ for each increment and after the cylindrical Teflon mold was removed, additional $20 \mathrm{sec}$ visible light was applied. As a result, 4 groups were fabricated as shown in (Figure 10).

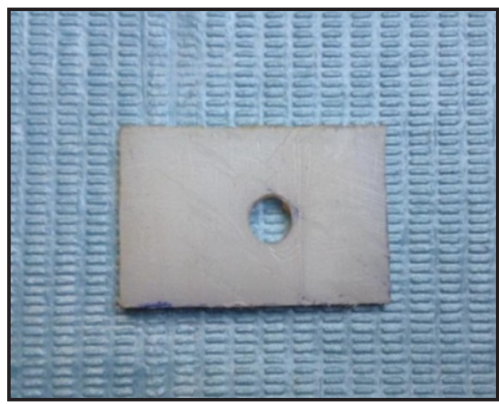

Fig. (9) Cylinderical Teflon mold for composite repair material build up

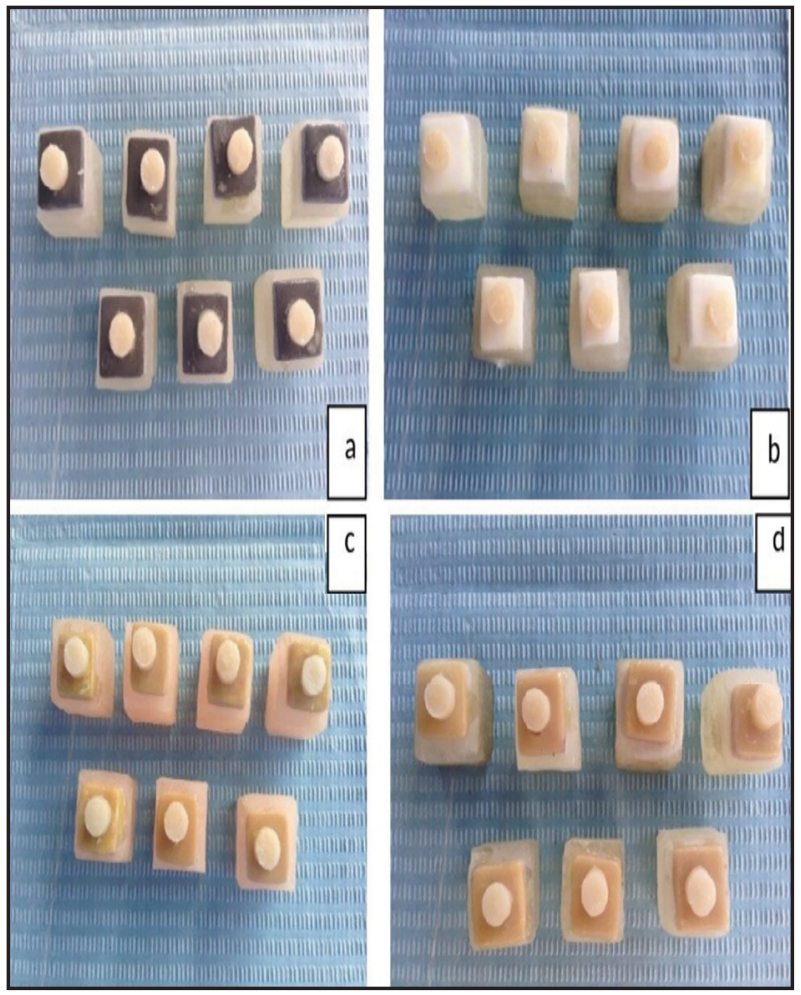

Fig. (10) a) Composite repair material discs bonded to metal specimens (M group). b) Composite repair material discs bonded to zirconia specimens ( $\mathrm{Z}$ group). c) Composite repair material bonded to VPM (VPM group). d) Composite repair material bonded to VPZ (VPZ group). 


\section{Storage, thermocycling}

All samples were stored in $37^{\circ} \mathrm{C}$ distilled water for 7 days ${ }^{(8,9)}$ for complete polymerization of the resin composite material followed by 1000 thermocycles at $\left(5\right.$ and $55^{\circ} \mathrm{C}$, with a 30 second dwell time) using a custom made thermocycling machine (Figure 11).

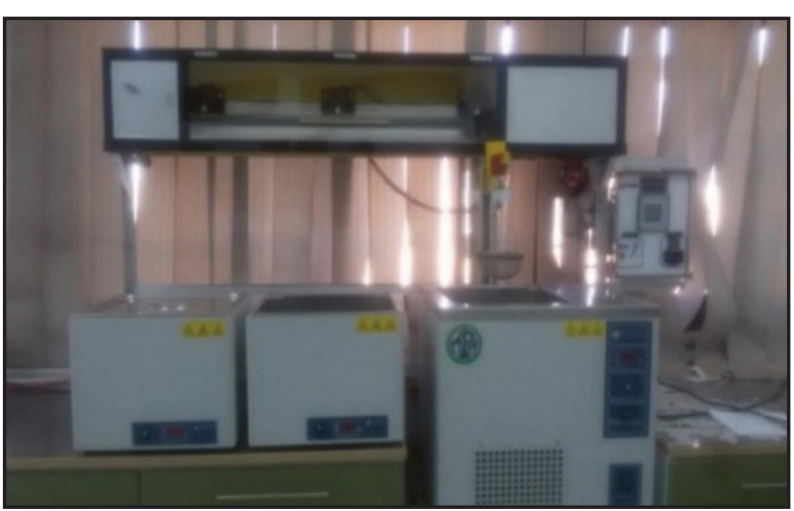

Fig. (11) Thermocycling machine

\section{Shear bond strength test}

Shear bond strength (SBS) was determined with a computerized universal testing machine (TIRA test 2805, Tira GmbH, EisfelderStrabe 23/25 D-9528, Schalkau, Germany) (Figure 12). The samples were fixed by jig and a chisel tip was used to direct a parallel shearing force as close as possible to the resin/ substrate interface with a cross head speed $0.5 \mathrm{~cm} /$ min (Figure 13). The maximum load was obtained in Newten when the composite resin cylinder was separated from the specimen surface, until debonding. The SBS was expressed in Mega pascals (Mpa) as shown in the following formula ( $\mathrm{SBS}=\mathrm{F} /$ where $\mathrm{F}$ is a load force at fracture in Newtens and $r$ is the radius of the resin composite cylinders in meters and. All data were collected and tabulated.

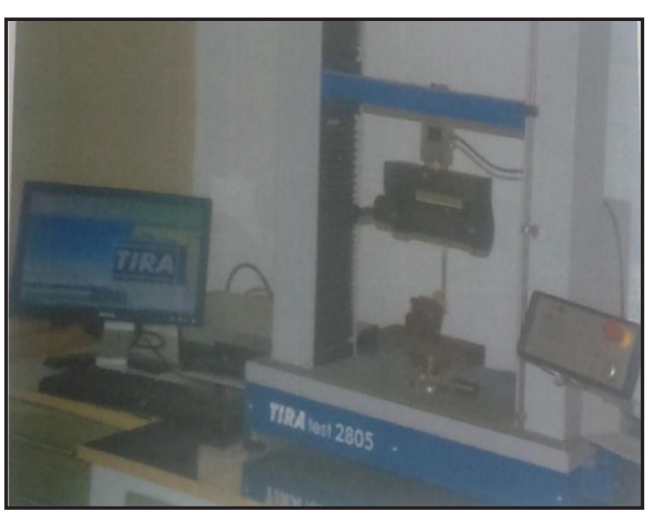

Fig. (12) Universal testing machine

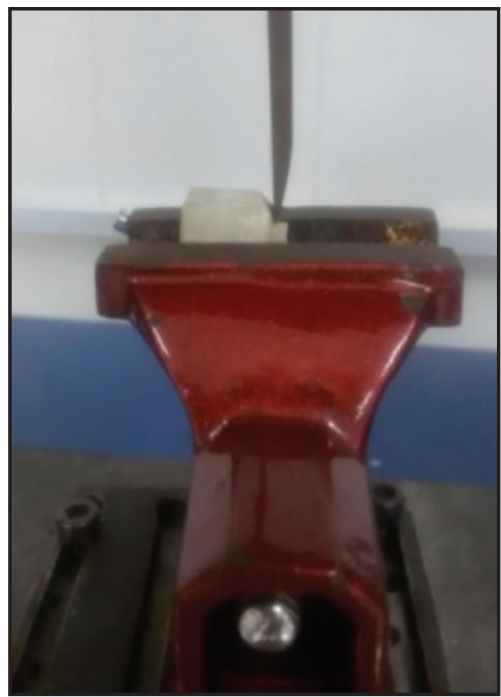

Fig. (13) Shear sample mounted on the universal testing machine for shear bond test using chisel edge blade

\section{Statistical analysis}

Results of shear bond strength test were tabulated and statistically analyzed using analysis of variance test (two way ANOVA) at a 95\% confidence level. Analysis of variance two way ANOVA) was used for comparison of means of more than two groups. Each two groups were compared with Student t-test. Lowest significant difference (LSD) statistical test was used to determine the significant difference between the tested groups. 


\section{RESULTS}

Shear bond strength of composite repair material to metal group (M group) versus that to veneering porcelain for metal group (VPM group):

The mean shear bond strength of metal " $M$ group" was $(16.33 \pm 2.47 \mathrm{MPa})$ and that of veneering porcelain for metal "VPM group" was $(12.12 \pm 1.07$ $\mathrm{MPa})$. The results showed a statistically significant difference between the two groups $(\mathrm{p}=0.001)$ as shown in Table (1) and Figure (14).

Table (1): Mean and (SD) values in MPa of shear bond strength in metal $(M)$ group and veneering porcelain for metal (VPM) group .

\begin{tabular}{|c|c|c|c|}
\hline Items & Metal group & $\begin{array}{c}\text { Veneering porcelain } \\
\text { for metal group }\end{array}$ & $\mathrm{p}$-value \\
\hline Mean $\pm \mathrm{SD}$ & $16.33 \pm 2.47$ & $12.12 \pm 1.07$ & $\mathrm{p}=.001 *$ \\
\hline
\end{tabular}

${ }^{*} p \leq 0.05$ indicate significant difference

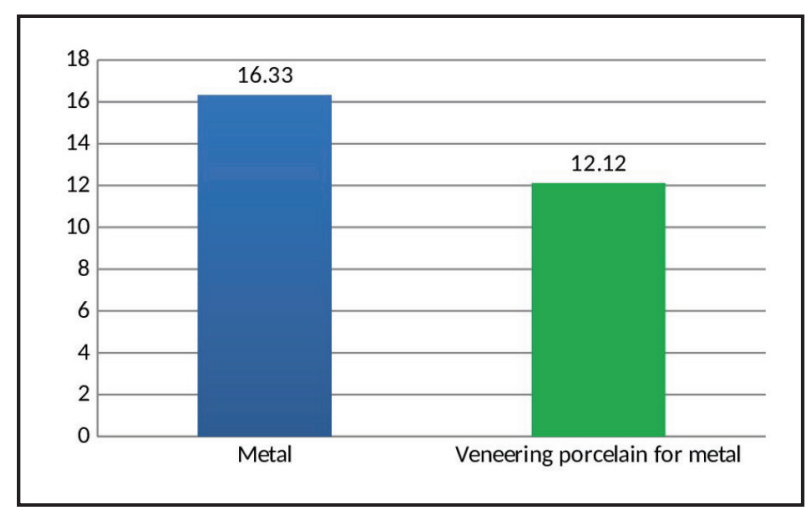

Fig. (14) Means and (SD) values in MPa of shear bond strength of the metal (M) group and the veneering porcelain for metal (VPM) group.

Shear bond strength of composite repair material to zirconia group ( $\mathrm{Z}$ group) versus that to veneering porcelain for zirconia group (VPZ group):

Mean shear bond strength of zirconia group was $(14.41 \pm 1.99 \mathrm{MPa})$ while that of veneering porcelain for zirconia group was $(10.41 \pm 1.1 \mathrm{MPa})$ as shown in Table (2) and Figure (15). The results revealed statically significant difference between the mean SBS of zirconia group and zirconia-veneering porcelain $(\mathrm{p}<0.05)$.

Table (2): Mean and (SD) values in MPa of shear bond strength of the zirconia $(Z)$ group and the veneering porcelain for zirconia (VPZ) group.

\begin{tabular}{|c|c|c|c|}
\hline Items & $\begin{array}{c}\text { Zirconia } \\
\text { group }\end{array}$ & $\begin{array}{c}\text { Veneering porcelain } \\
\text { for Zirconia group }\end{array}$ & $\mathrm{p}$-value \\
\hline $\begin{array}{c}\text { Mean } \pm \\
\text { SD }\end{array}$ & $14.41 \pm 1.99$ & $10.41 \pm 1.14$ & $\mathrm{p}=.001^{*}$ \\
\hline
\end{tabular}

${ }^{*} p \leq 0.05$ indicate significant difference

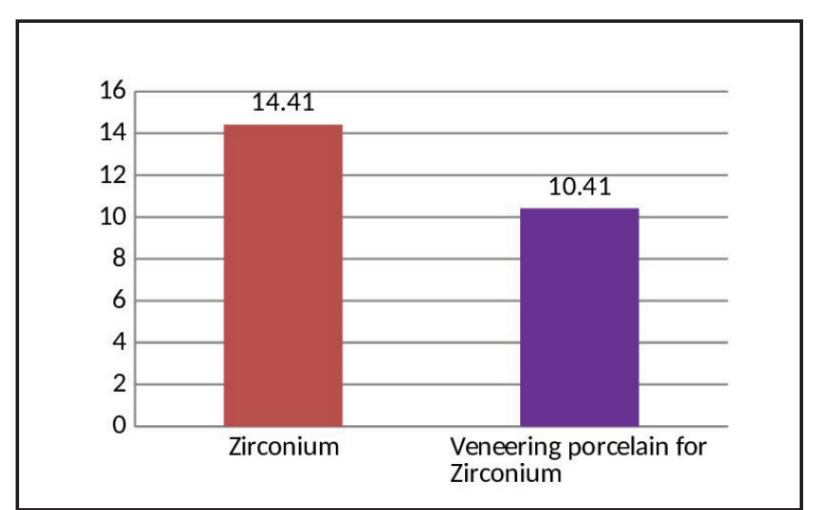

Fig. (15) Mean and (SD) values in MPa of shear bond strength of the zirconia $(\mathrm{Z})$ group and the veneering porcelain for zirconium (VPZ) group.

\section{Shear bond strength of composite repair material} to metal group (M group) versus that to zirconia group ( $\mathrm{Z}$ group):

Mean shear bond strength of metal group was $(16.33 \pm 2.47 \mathrm{MPa})$ and of zirconia group was $(14.41 \pm 1.99 \mathrm{MPa})$. The results showed insignificant differences $(p>0.05)$ between the two groups as shown in Table (3) and Figure (16). 
Table (3): Means and (SD) values of shear bond strength in $M P a$ of the metal (M) group and the zirconia $(Z)$ groups.

\begin{tabular}{|c|c|c|c|}
\hline Items & Metal group & Zirconia group & $\mathrm{p}$-value \\
\hline Mean $\pm \mathrm{SD}$ & $16.33 \pm 2.47$ & $14.41 \pm 1.99$ & $\mathrm{p}=.136^{*}$ \\
\hline
\end{tabular}

${ }^{*} p>0.05$ indicate insignificant difference

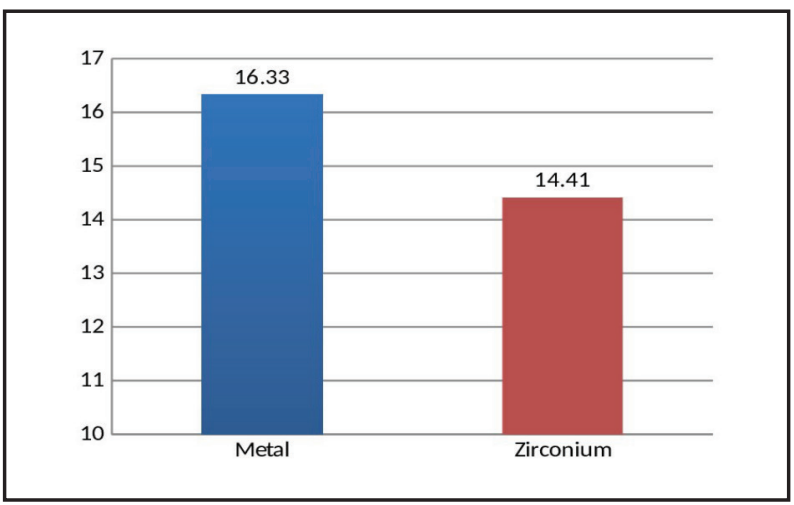

Fig. (16) Mean and (SD) values in MPa of shear bond strength of the metal (M) group and the zirconia $(\mathrm{Z})$ group.

Shear bond strength of composite repair material to veneering porcelain for metal group (VPM group) versus that to veneering porcelain for zirconia group (VPZ group):

Mean shear bond strength of veneering porcelain for metal group was $(12.12 \pm 1.07 \mathrm{MPa})$ and that of veneering porcelain for zirconia group was $(10.41 \pm 1.14 \mathrm{MPa})$. The results showed statistically significant difference between the two groups $(\mathrm{p}<0.05)$ as shown in Table (4) and Figure (17).

Table (4): Means and (SD) values of shear bond strength in $M P a$ of the veneering porcelain for metal (VPM) group and the veneering porcelain for zirconium (VPZ) group.

\begin{tabular}{|c|c|c|c|}
\hline Items & $\begin{array}{c}\text { Veneering por- } \\
\text { celain for metal } \\
\text { group }\end{array}$ & $\begin{array}{c}\text { Veneering } \\
\text { porcelain for } \\
\text { Zirconium group }\end{array}$ & $\mathrm{p}$-value \\
\hline Mean $\pm \mathrm{SD}$ & $12.12 \pm 1.07$ & $10.41 \pm 1.14$ & $\mathrm{p}=.014^{*}$ \\
\hline
\end{tabular}

$* p<0.05$ indicate significant difference

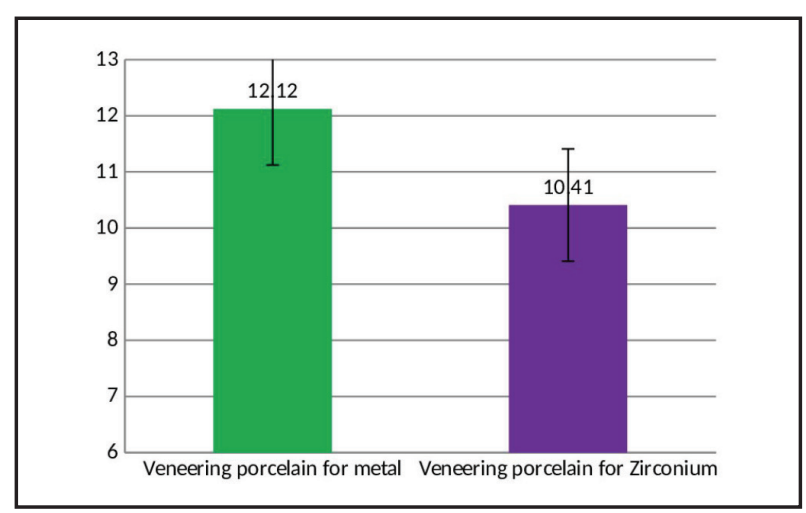

Fig. (17) Means and (SD) values in MPa of shear bond strength of veneering porcelain for metal (VPM) and veneering porcelain for zirconia (VPZ) group.

\section{DISCUSSION}

\section{Sandblasting for metal and zirconium groups:}

Metal and zirconia specimens received chair side airborne particle abrasion with $50 \mu \mathrm{m}$ aluminum oxide $\left(\mathrm{Al}_{2} \mathrm{O}_{3}\right)$ particles at 2 bar pressure using an intraoral air abrasion device for $20 \mathrm{sec}$ from a distance of $10 \mathrm{~mm}$ perpendicularly to the surface in agreement with previous studies ${ }^{(10)}$. Metal (Nickel Chromium alloy) sandblasting with $\mathrm{Al}_{2} \mathrm{O}_{3}$ particles can form a passive film made of oxides that bond to reactive groups contains bonding agent. Also performed to mechanically clean the surface and increasing surface energy and the activity of the surfaces ${ }^{(11)}$. As zirconia is resistant to traditional acid etching treatments due to its silica and glass-free polycrystalline structure. The current study use sandblasting to increase surface roughness and also allow formation zirconium oxide layer to improve resin-zirconia bond strength by a chemical bond with phosphate ester group of MDP containing bond ${ }^{(12)}$. The efficacy of sandblasting depend on various factors like the size of particles, air pressure, distance, angle and duration of procedure ${ }^{(13)}$. The current study selected $50 \mu \mathrm{m}$ as a sample size not only because $50 \mu \mathrm{m}$ particles are the most commonly used alumina articles 
for sandblasting ${ }^{(14)}$, but also small particle size of $50 \mu \mathrm{m}$ easily flows out of spray tip with greater number of particles than coarse powder of $110 \mu \mathrm{m}$, consequently a greater number of particles are left on the surface of the tested materials producing more abrasive than coarse powder. ${ }^{(15)}$ Sandblasting with $110 \mu \mathrm{m}$ and $250 \mu \mathrm{m}$ aluminia $\mathrm{Al}_{2} \mathrm{O}_{3}$ has the potential to remove significant amounts of substances and could affect the clinical adaptation of the prostheses $^{(16)}$. Air abrasion pressure selected at 2 bars as it causes insignificant damage to the surface. Also because impact particles at high speed creates residual compressive stresses damages some superficial areas ${ }^{(17)}$. In contrast Moon et al $2016^{(18)}$ recommended sandblasting with $50 \mu \mathrm{m}$ aluminum particles under 4 bar pressure achieve a maximum bond strength to resin cement. Angle and distance between the nozzle and the surface was selected at $10 \mathrm{~mm}$ and $90^{\circ}$ angle at this study because this provide sufficient surface roughness in agreement with previous studies $^{(19)}$.

Duration of sandblasting was selected in this study for $20 \mathrm{sec}$ because sandblasting for a long time causes sharp margins in surface topography that act stress points lead to formation and propagations of cracks that can adversely affect the fracture resistance of restoration ${ }^{(20)}$.

\section{Hydroflouric acid etching for porcelain groups (VPM group and VPZ group):}

Hydrofluoric acid used in this study to dissolve the crystalline and the glassy phases and produces a porous irregular surface that increases the surface area and facilitates the penetration of the resin into the micro-retentions of the etched ceramic surfaces $^{(21)}$.

Etching of feldspathic porcelain is a dynamic process depends on substrate constitution, surface topography, acid concentration and etching time ${ }^{(22)}$.
Increase silica content in ceramic allows more surface roughness especially when Hydrofluoric acid used for etching as HF reacts selectively with silica and produce hexafloruosilicate complex which is responsible for surface roughness and facilitate interlocking of the resin composite ${ }^{(23)}$. Concentration $8 \% \mathrm{HF}$ acid used in this study in agreement with Alex (2008) ${ }^{(24)}$ that reported that HF concentration in typical dental applications should be between $4 \%$ to $10 \%$ to be safe for intraoral repair. Also at low concentration (5 and 10\%) feldspathic porcelain surface was preferentially corroded and roughened for good bonding while at higher concentration (20\% concentration) ,new defects appear on porcelain surface that adversely affect bond strength with resin. ${ }^{(22)}$ Regarding the etching time, the present study use HF acid at duration $60 \mathrm{sec}$ because this time provide acceptable ceramic roughness according to manufacturer instructions. Also because etching period above $30 \mathrm{sec}$ effectively enhanced the bond strength to resin. ${ }^{(25)}$ While etching longer than $60 \mathrm{sec}$, increases the occurrence of cohesive failure in ceramic material. ${ }^{(26)}$ Filtek Z350 XT composite nano-hybrid composite were used in the current study because its filler content is lesser than the micro-hybrid composite that make it easily impregnated in the roughened surface result in enhanced bond strength to different surfaces when air abrasion was used as surface treatment ${ }^{(27)}$. The use of nanocomposite resins allows better nano-bonding interface between the tooth structure and the restorative material resulting in a more stable and natural interface $^{(28)}$.

Single bond universal adhesive used in the current study as it contains the most important component, MDP monomer (methacryloxydecyldihydrogenphosphate) that has been shown to have good bonding properties to base metal alloys ${ }^{(29)}$ and good bonding to zirconia ${ }^{(30)}$. Aging of dental material 
before testing by immersion in water either with or without thermocycling is a common protocol for evaluation of material behavior under clinically relevant conditions ${ }^{(31,32)}$. Thermocycling at $5^{\circ} \mathrm{C}$ to $55^{\circ} \mathrm{C}$ is a procedure performed before temperature variations during eating, drinking and breathing ${ }^{(33)}$. Several factors in thermocycling can affect the bond strength test results such as temperature setting, dwell time and number of cycles. The latter is the most effective parameters in this respect where the more thermal cycle numbers lead to decrease the bond strength value ${ }^{(34)}$. The reason to subjects specimens in this study for 1000 cycles not only in agreement with many studies ${ }^{(35)}$. But also because number of cycles selected by manufacturer before microleakage test for single bond universal adhesive was 850 cycles. The results of the current study showed that shear bond strength of composite repair material with base metal group was higher than with zirconia group and the difference was insignificant. This situation maybe resulted from MDP content of single bond universal adhesive that revealed great chemical bonding properties for base metal alloys due to increase metal oxides than zirconia ${ }^{(7)}$. The results of this study recorded the bond of composite repair material was higher with veneering porcelain for metal (VMK95) than with veneering porcelain for zirconia (VM9) and the difference was significant between two groups. The reason due to the differences in the composition and microstructure of two types of veneering porcelain might affect the surface texture and bond strength between the ceramics and resin. Vita VMK95 contain in its composition more silica (about $68 \%)^{(36)}$ than Vita VM9 (about 60\%) ${ }^{(37)}$ which dissolved by HF acid leaving more rough surface where HF acid react selectively with silica creating a micro retentive surface which facilitates the interlocking of the resin composite ${ }^{(38)}$.

\section{CONCLUSIONS}

Within the limitations of this in vitro study:

Sandblasting and application of single bond universal adhesive containing MDP can be recommended for repair metal and zirconium surfaces with composite material. HF acid etching and application of single bond universal adhesive containing MDP can be recommended for repair VPM and VPZ with composite repair material.

\section{REFERENCES}

1. Latta M and Barkmeier W. Approaches for intraoral repair of ceramic restorations. Compend Contin Educ Dent. 2000; 21(8):635-9, 642-644.

2. Pameijer C , Louw $\mathrm{N}$ and Fischer D. Repairing fractured porcelain: how surface preparation affects shear force resistance. J Am Dent Assoc. 1996; 127:203-209

3. Tarozzo A, De Mattos C, Ribeiro F and Semprini M. Comparison of retentive systems for composites used as alternatives to porcelain in fixed partial dentures. J Prosthet Dent. 2003;89:572-578

4. Buonocore MG. A simple method of increasing the adhesion of acrylic filling materials to enamel surfaces. J Dent Res. 1955; 34:849-853

5. Beck DA, Janus CE and Douglas HB. Shear bond strength of composite porcelain repair materials bonded to metal and porcelain. J Prosthet Dent. 1990; 64:529-533.

6. Han IN., Kang DW., Chung CH, Choe HC. and Son MK. Effect of various intraoral repair systems on the shear bond strength of composite resin to zirconia. J Adv Prosthodont 2013;5:248-55

7. Yoo JY., Yoon HI., Park JM. and Park EJ. Porcelain repair - Influence of different systems and surface treatments on resin bond strength . J Adv Prosthodont. 2015;7:343-348

8. An HS, Park JM and Park EJ. Evaluation of shear bond strengths of gingiva-colored composite resin to porcelain, metal and zirconia substrates. J Adv Prosthodont. 2011;3(3): 166-171

9. Gulsum Sayin Ozel and Ozgur Inan. Comparison of the Shear Bond Strength of Three Different Composite Materials to Metal and Ceramic Surfaces. International Journal of Composite Materials 2016; 6(4): 121-128 
10. Shayegh S.SH. , Amini P., Yaghmai K., Massoumi F. and Abbasi K. Comparison of the Effect of Three methods of Porcelain Surface Treatment on Shear Bond Strength of Composite to Porcelain .Journal of Islamic Dental Association of IRAN (JIDAI) Spring 2016 ;28 (2):72-75

11. Yoshida K, Kamada K, Atsuta M. Adhesive primers for bonding cobalt-chromium alloy to resin. J Oral Rehabil. 1999; 26(6):475-478

12. Seabra B, Arantes-Oliveira S and Portugal J. Influence of multimode universal adhesives and zirconia primer application techniques on zirconia repair. J Prosthet Dent. 2014; 112:182-187.

13. Della Bona A, Bora M, Benetti P and Cecchetti D. Effect of surface treatments on the bond strength of a zirconia-reinforced ceramic to composite resin. Braz Oral Res.2007;21:10-15

14. Attia A and Kern M. Long-term resin bonding to zirconia ceramic with a new universal primer. J Prosthet Dent. 2011; 106:319-327

15. Kern M and Thompson VP. Sandblasting and silica-coating of dental alloys: volume loss, morphology and changes in the surface composition. Dent Mater 1993;9:151-61

16. Cifti Y, Caly S and Hersk N. Shear bond strength evaluation of different veneering systems on $\mathrm{Ni}-\mathrm{Cr}$ alloys. J Prosthodont. 2007; 16:31-36

17. Zhang Y, Lawn BR, Rekow ED and Thompson VP. Effect of sandblasting on the long-term performance of dental ceramics. J Biomed Mater Res B Appl Biomater 2004;71:381-386

18. Moon YH, Lee J and Lee MG. Shear bond strength of dental CAD-CAM hybrid restorative materials repaired with composite resin. The Korean Academy of Prosthodontics. 2016;54:193-202

19. Zeighami S, Gheidari A, Mahgoli H, Rohanian A and Ghodsi S. Effect of sandblasting angle and distance on biaxial flexural strength of zirconia-based ceramics. J Contemporary Dent Practice 2017;18:443-447

20. Salehi EA, Heshmat H, Salehi EM and Kharazifard MJ. In vitro evaluation of the effect of different sandblasting times on the bond strength of feldspathic porcelain to composite resin. J Islamic Dent Assoc of Iran (JIDAI). 2013; 25: $22-30$
21. Ozcan M, Vallittu P, Peltomaki T, Huysmans M and Kalk W. Bonding polycarbonate brackets to ceramic: Effects of substrate treatment on bond strength. Am J Orthod and Dentofacial Orthop. 2004; 126:220-227

22. Addison O, Marquis PM and Fleming G.J. The impact of hydrofluoric acid surface treatments on the performance of a porcelain laminate restorative material. Dent Mater. 2007;23:461-468.

23. Yen TW, Blackman RB and Baez RJ. Effect of acid etching on the flexural strength of a feldspathic porcelain and a castable glass ceramic. J Prosthet Dent 1993;70:224-233

24. Alex G. Preparing porcelain surfaces for optimal bonding. AEGIS dental networks 2008;2:16

25. Chen J, Matsumura H and Atsuta M. Effect of etchant, etching period, and silane priming on bond strength to porcelain of composite resin. J Oper Dent. 1998; 23:250-257

26. Wolf DM, Powers JM and Okeefe KL. Bond strength of composite to etched and sandblasted porcelain. Am J Dent $1993 ; 6: 155-158$

27. Blatz BM, Dent M, Sadan A and Kern M. Resin-ceramic bonding: a review of literature. J Prosthet Dent. 2003; 89:268-274

28. dentistry: Nanotechnology. Int J Nanomed. 2011;6:27992804

29. Yoshida K, Taira Y, Matsumura $\mathrm{H}$ and Atsuta M. Effect of adhesive metal primers on bonding a prosthetic composite resin to metals. J Prosthet Dent. 1993; 69:357-362

30. Piascik JR, Swift EJ, Braswell K and Stoner BR. Surface fluorination of zirconia: adhesive bond strength comparison to commercial primers. Dent Mater. 2012;28:604-608.

31. Palin W.M, Fleming G.J, Burke F.J, Marquis P.M and Randall R.C. The influence of short and medium-term water immersion on the hydrolytic stability of novel lowshrink dental composites. Dent Mater 2005; 21:852-863

32. Curtis A.R, Shortall A.C, Marquis P.M and Palin W.M. Water uptake and strength characteristics of a nanofilled resin-based composite. J Dent 2008;36:186-193

33. Leibrock A, Degenhart M, Behr M, Rosentritt $M$ and Handel G. In vitro study of the effect of thermo- and loadcycling on the bond strength of porcelain repair systems. J Oral Rehabil. 1999;26:130-137 
34. Amaral FL, Colucci V, Palma-Dibb RG and Corona SA. Assessment of in vitro methods used to promote adhesive interface degradation: a critical review. J Esthet Restor Dent. 2007;19:340-353

35. Dos Santos JG, Fonseca RG, Adabo GL and Dos Santos CA. Shear bond strength of metal-ceramic repair systems. J Prosthet Dent. 2006; 96(3):165-173

36. Kukiattrakoon B and Thammasitboon k. Optimal acidulated phosphate fluoride gel etching time for surface treat- ment of feldspathic porcelain: on shear bond strength to resin composite. Eur J Dent 2012;6:63-69

37. Almeida-Ju' nior AA, Longhini D, Domingues NB, Santos $\mathrm{C}$ and Adabo GL. Effects of extreme cooling methods on mechanical properties and shear bond strength of bilayered porcelain/3Y-TZP specimens journal of dentistry $.2013 ; 41: 356-362$

38. Abdul-Hag A, Edward J and Jorje P. Effects of surface treatment and bonding agents on bond strength of composite resin to porcelain. J Prosthet Dent. 1993; 70: 118-120 